\title{
Compensating active power imbalances in power system with large-scale wind power penetration
}

\author{
Abdul BASIT ${ }^{1,2}$, Anca D. HANSEN ${ }^{1}$, Mufit ALTIN ${ }^{1}$, \\ Poul E. SØRENSEN ${ }^{1}$, Mette GAMST ${ }^{3}$
}

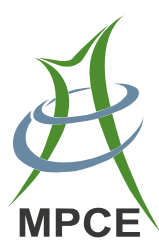

\begin{abstract}
Large-scale wind power penetration can affect the supply continuity in the power system. This is a matter of high priority to investigate, as more regulating reserves and specified control strategies for generation control are required in the future power system with even more high wind power penetration. This paper evaluates the impact of large-scale wind power integration on future power systems. An active power balance control methodology is used for compensating the power imbalances between the demand and the generation in real time, caused by wind power forecast errors. The methodology for the balance power control of future power systems with large-scale wind power integration is described and exemplified considering the generation and power exchange capacities in 2020 for Danish power system.
\end{abstract}

Keywords Wind power plant, SimBa, Centralized or decentralized combined heat and power plant, Automatic generation control

CrossCheck date: 16 January 2015

Received: 19 June 2014 / Accepted: 20 January 2015/

Published online: 14 July 2015

(C) The Author(s) 2015. This article is published with open access at Springerlink.com

$\bowtie$ Abdul BASIT

a_basitkhan@hotmail.com

1 Department of Wind Energy, Technical University of Denmark, Frederiksborgvej 399, 4000 Roskilde, Denmark

2 Sino-Danish Center for Education and Research, Niels JensensVej 2, 8000 Aarhus, Denmark

3 Energinet.dk, Tonne Kjærsvej 65, 7000 Fredericia, Denmark

\section{Introduction}

The first task of any transmission system operator (TSO) is to maintain a reliable and secure power system operation and afterwards to minimize the production cost, even in conditions with large-scale wind power penetration. The wind speed forecast in a power system withlarge-scale wind power integration plays an important role in the power balance planning. An incorrect wind speed forecast can deviate the generation and the power exchange plan with neighbouring power systems in a cost-effective way. This can lead to power system balancing and control problems, and introduces several challenges in maintaining a reliable and secure power system operation [1]. In spite of these challenges, the interest in the integration of largescale wind power into power systems has motivated and enhanced new opportunities for modelling and controlling of power system. Adequate methodologies for studying power system dynamics and control, like the present one, on the active power balance control, are of especial relevance for the future power systems.

Several studies [2-5] on active power balancing in a power system with large-scale wind power integration have been performed over the years. In [2], the performance of the secondary control action and the regulating power control from conventional power plants is analyzed, while in [3] it is stated that response of the thermal power plants used in power balance control is mainly determined by their active power ramp rate. In [4], a Dutch case study is described to assess the automatic generation control (AGC) performance in the presence of large-scale wind power and it is concluded that additional reserves from thermal power plants are required for keeping the area control error at the same level. Recent Chinese studies [5] show that the power imbalances from wind power plants (WPPs) can be 
controlled by conventional generators. Nevertheless, further studies and control methodologies for balancing the active power in power systems with power system withlarge-scale wind power integration, taking into account hour-ahead dispatch power plan for generating plants and power exchange with neighbouring power systems, are necessary to enhance the stability of future power systems with large-scale wind power integration. In this respect, conventional market models are important to be considered as well, as they are simulating optimal unit commitment and dispatch of power plants with one hour resolution [6]. However, in order to manage the wind power forecast errors in a large scale wind power integrated power system, a dispatch plan for the power plants with a smaller resolution than one hour is necessary.

In a large interconnected power system, the power balance is one of the main challenges that need to be evaluated for large-scale integration of wind power. The paper presents a new methodology for active power balance control in future interconnected power system with large scale wind power penetration. The proposed control methodology uses an hour-ahead regulating power plan in a time scale of five minutes to compensate the real time active power imbalances in the power system. The methodology can be used as a guideline for the TSOs, to investigate their power balancing capabilities considering WPPs. The Danish power system is used for the implementation and the verification of the methodology because of its big wind power penetration goal quote, i.e., $50 \%$ of the total electricity production from wind power by 2020 [7].

The paper is structured as follows: a brief description of the impact of the fluctuated nature of the wind on the power system operation is provided firstly. Then, the proposed active power balance control methodology is described, approaching also the aspects regarding the AGC and the generation of the hour-ahead regulating power plan. The high wind penetration scenarios for the Danish power system by 2020 are used to assess the performance of the methodology through a set of simulations with the developed Danish power system model. Finally, conclusive remarks are reported in the final section.

\section{Impacts of wind power on power system operation}

The wind speed is always fluctuating, and so is the power generated from wind turbines (WTs). The fluctuating and uncertain nature of wind may introduce several challenges in the maintenance of the power balance in a power system with large-scale wind power integration. No matter what TSOs have the responsibility to preserve a reliable power system operation and ensure a secure power supply, while keeping the generation at lowest possible cost.

Active power reserves are always needed to keep the power system in balance and their amount also depends on the level of wind power penetration into the power system and on forecasted weather conditions. For example, extreme weather conditions may result in a loss of large amount of wind power within a few minutes, thus jeopardizing the reliability and the security of the power system operation [1]. Therefore, reserves are typically needed for fast conventional generating units to increase the system reliability and ensure the power supply security. According to European Network of Transmission System Operators for Electricity (ENTSO-E), the type of reserves for keeping the power system in balance can be classified as Frequency Containment Reserves (FCRs), Frequency Restoration Reserves (FRRs) and Replacement Reserves (RRs) [8, 9]. FCRs are activated automatically and locally within $30 \mathrm{~s}$ for constant containment of frequency deviations and to constant maintenance of the power balance in the whole synchronously interconnected system. FRRs are typically activated (manually or automatically) within $15 \mathrm{~min}$, in order to maintain the active power balance in the power system and the power exchange with neighbouring power system on its schedule. RRs respond in several minutes up to hours and restores the FCRs and FRRs back to the required level. The total volume of FCRs in Continental Europe and Nordic region is \pm 3000 and $\pm 600 \mathrm{MW}$, respectively [9]. However, as wind power impacts the power system operation, it is predicted that more reserves will be needed in the future to accommodate large amount of wind power into the power systems. In this study the power imbalance is controlled through FCRs and FRRs. Conventional and wind power plants provides the FCRs, while FRR is activated only by conventional power plants through AGC.

\section{Active power control methodology}

A methodology for controlling the active power imbalance in a power system with large-scale wind power is presented. The proposed methodology uses an hour-ahead regulating power plan in a time scale of $5 \mathrm{~min}$ for the power plants and power exchange in neighbouring power systems. The following subsections explain the generation of hour-ahead regulating power plan by a balancing program and the AGC model developed for this study.

\subsection{Hour-ahead regulating power plan}

The generated power in a power system is typically traded by the balancing responsible companies on the spot- 
market [7]. Two standard power balancing programs, called the WILMAR and the SimBa, are used to generate the day-ahead and hour-ahead time series. WILMAR stands for Wind Power Integration in Liberalised Electricity Markets, while SimBa stands for simulation power balancing. A detailed description of these programs is out of the scope of the paper. However, more details on WILMAR and SimBa can be found [7, 10-14].

The WILMAR is an example of a program for modelling the spot market as a perfect market with a unit commitment and dispatch model. The hourly bids for purchase and sale are selected one day prior to physical delivery and therefore referred as a day-ahead market. In this process, the bids are selected with foremost intent of preserving system integrity and minimizing the overall operating cost. The bid selection is subjected to different constraints, such as transmission constraints in the electricity system and capacity constraints of storage and generation technologies.

The day-ahead agreements come out of the balance because of wind power forecast errors or unavailability of generating units. The power balance can be restored by trading on an intra-day balancing power market. For example, based on updated forecasts, the Danish TSO uses the Nordic operational information system (NOIS) list and generates an hour-ahead plan for the intra-hour balance with 5 min resolution, through simulations with a dedicated power balancing program, called the SimBa [7, 14]. SimBa can model the power system in detail, taking the current grid regulations and the energy market rules into account. It uses the inputs from unit commitment models including hourly values for energy production, load and the power exchange between interconnected areas. These inputs to the SimBa program are provided by a WILMAR model, while Correlated Wind power fluctuations (CorWind) model provides the day-ahead and hour-ahead forecasts of wind power, and the available wind power.

With the balanced hourly time series provided by WILMAR, SimBa starts to update the day-ahead schedule with a 5 min time resolution, taking in account the ramping on interconnection lines and power plants. It then estimates the fluctuations from hour-ahead wind power forecast and generates the possible wind power schedule in a 5 min resolution within the operating hour. Based on the possible wind power schedule and the updated day-ahead schedule, SimBa calculates the mean imbalance for half an hour and balances the power system internally in different areas, considering the grid regulation, transmission losses and transmission constraints. It activates the bids from NOIS list, while taking in account the minimum activation time (30 $\mathrm{min})$ and minimum bid level (10 MW) [14]. With above mentioned constraints, $\mathrm{SimBa}$ then provides the balanced hour-ahead plan for generation units and power exchange with neighbouring power

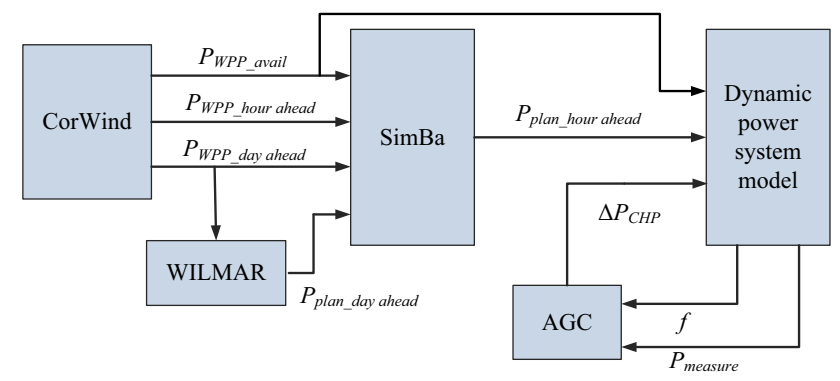

Fig. 1 Signals among CorWind, WILMAR, SimBa, the dynamic power system model and AGC

systems with five minute resolution. Fig. 1 illustrates how SimBa, based on the inputs from CorWind and WILMAR, generates the hour-ahead input to the dynamic power system model, where the AGC is acting.

SimBa creates an upward and downward regulation list of bids based on the marginal cost function, bidding price and production capacity for each unit. Due to the uncertain nature of wind, the wind power within the operating hour cannot be the same as its estimated value, thus it can create power imbalance within the operating hour. This imbalance is partially compensated by FRR, i.e., through the activation of additional regulating bids in the control room from the NOIS list and with an AGC which has reserved capacity of $\pm 90 \mathrm{MW}$, and it acts on the border of Western Denmark with Germany [7]. However, for the present investigation, it is assumed that the power imbalance within the operating hour is controlled only through AGC, by providing $\Delta P_{S E T}$ to the conventional power plant (i.e., centralised combined heat and power plant (CHP)) as a secondary response. $\Delta P_{S E T}$ represents the required change in the participating generating power set points in the imbalanced area.

\subsection{Automatic generation control (AGC)}

The AGC is used to routinely balance the power system and to make the power system operation more reliable [15]. The AGC, developed and implemented in this investigation, is sketched in Fig. 2. The goal of the AGC, depending on available secondary power, is to reduce the area control error $\left(P_{A C E}\right)$ to zero. The $P_{A C E}$ is calculated based on the change in system frequency $(\Delta f)$ and on a possible power mismatch $(\Delta P)$ among generations, power exchange and system load, as follows:

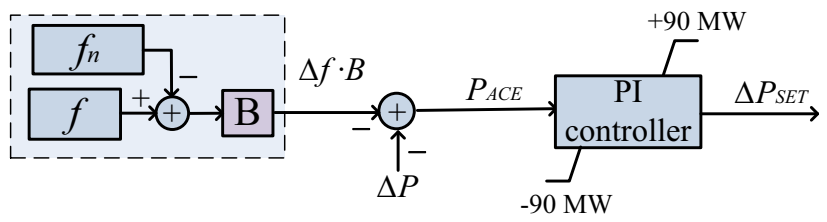

Fig. 2 AGC model 
$P_{A C E}=-\Delta P-(\Delta f \cdot B)$

$\Delta P=P_{G}-P_{\text {exchange }}-P_{\text {load }}$

where $P_{G}$ is the power generated by CHPs, de-centralised combined heat and power plant DCHPs and WPPs in real time. The system frequency bias factor $B(\mathrm{MW} / \mathrm{Hz})$ is determined from the droop characteristics of all generating units taking part in the primary response. The frequency bias factor is reflecting the power ability (FCR) of the generating units to compensate for a frequency changes. The overall secondary response from AGC, i.e., $\Delta P_{S E T}$, is decided by a PI controller based on the equation shown below:

$\Delta P_{S E T}=K \times P_{A C E}+\frac{1}{T} \int P_{A C E}$

where $K$ and $T$ are the gain and integration time constant,. AGC with a capacity of $\pm 90 \mathrm{MW}$ is implemented to investigate the impact of large scale integration of wind power on future power systems during the power imbalances between demand and generation, caused by wind power forecast errors. The wind power is not integrated in AGC in this paper, as this will be a part of the next upcoming investigation.

\section{Simulation based validation of methodology}

As mentioned before, the Danish power system is used to validate the performance of the proposed active power control methodology. The following sub-sections will explain the future Danish power system model and a set of simulations assessing the performance of the proposed active power control methodology.

\subsection{Danish power system}

The developed Danish power system model reflects the most relevant dynamics of the power system with respect to active power balancing control issues. It includes models for the AGC system, centralised or de-centralised combined heat and power plant (CHP and DCHP), WPP and interconnections with neighbouring power system.

As the focus of this paper is on active power balance control, the transmission losses are ignored and the power system is designed as a two-bus system, as shown in Fig. 3. The system interconnections and the generating unit models in the Danish power system are explained below.

\subsubsection{System interconnection}

The Danish power system is composed of two power systems, i.e., Eastern and Western Danish power systems.

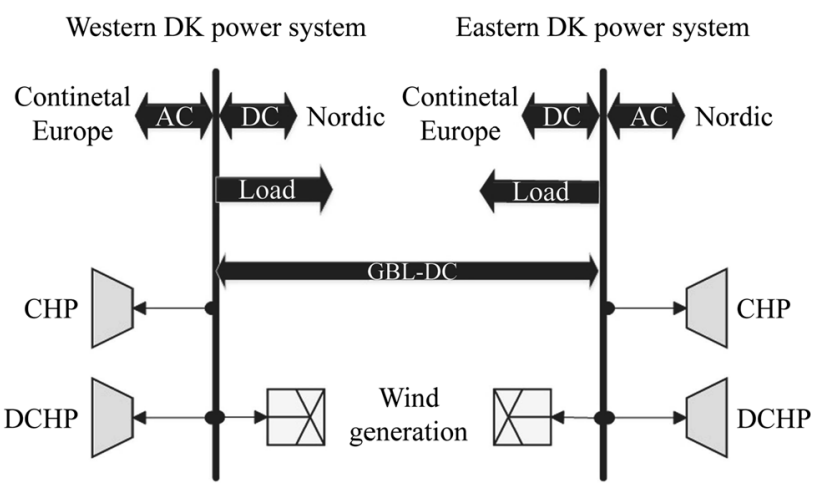

Fig. 3 Danish power system model

They are connected together through an HVDC connection, i.e., Great Belt Link (GBL) having a transmission capacity of $600 \mathrm{MW}$. They are also connected to the strong neighbouring power systems of Germany, Sweden and Norway. The Eastern Danish power system is synchronized with the Nordic power system, whereas the Western Danish power system is synchronized with the continental European power system. The interconnection capacities of Danish power system with its neighbouring powers as planned for the year 2020 are shown in Fig. 4 [16], where AC interconnections are presented as dotted line and DC interconnections as solid lines.

Denmark's neighboring power systems ramp the agreed power exchange in different durations and at different starting time. For example, in the Nordic power system, the agreed power exchange shall be ramped within $30 \mathrm{~min}$ and shall begin $15 \mathrm{~min}$ before the agreed exchange hour. Meanwhile, in the continental European power system, the power exchange shall be ramped within $10 \mathrm{~min}$ and shall start $5 \mathrm{~min}$ before the agreed exchange hour [15]. If the power has to be transported from the Nordic power system to the continental European power system or vice versa, the difference in power exchange ramping might lead to a power imbalance in Danish power system at an agreed hour.

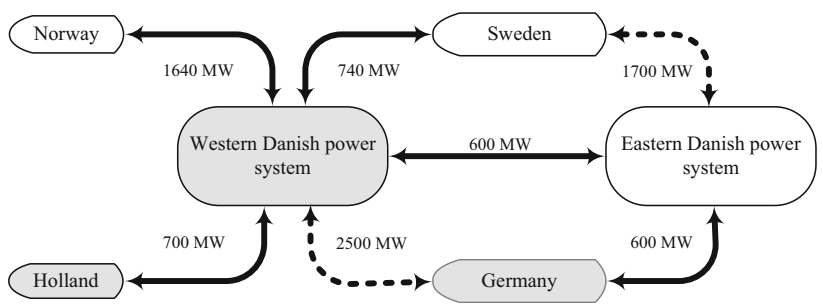

Fig. 4 Denmark interconnection capacities as planned for 2020 


\subsubsection{Electrical power generating units}

The electrical power generation in Denmark is a combination of conventional and renewable generation sources. The conventional power generation is typically based on CHPs and DCHPs, while renewable generation is basically from WPPs. In the following sections, the aggregated models of power generating units used in the Danish power system are briefly described, reflecting their most relevant dynamic features.

1) Conventional power plants

Aggregated models for CHP and DCHP are described in $[17,18]$. It is worth mentioning that, the response time and ramp rates associated with $\mathrm{CHP}$ are in order of minutes and they have dominant characteristic for power system studies. Shortly afterwards, an aggregated CHP model consists of a thermal boiler, a boiler turbine controller, a steam turbine, and a speed governor, while an aggregated DCHP model includes gas turbine and a speed governor.

In the proposed methodology, the reference power signal for CHP or DCHP is calculated based on the planned power from SimBa and the power correction is from the AGC. The speed governor of the generating units activates the FCR, if the frequency deviates by $\pm 0.01 \mathrm{~Hz}$. The amount of activated FCR depends on the droop characteristics of the governor of each generating unit, i.e., $4 \%$ in this paper.

2) Wind power plants

The aggregated modelling of WPP is commonly used to facilitate power system studies, where the concern is not on the performance of an individual WT, but rather on the impact of an entire WPP on the power system. The idea of using the aggregation method is to reduce computational effort, while maintaining the capability to predict the unit impact on system dynamic behaviour. A simplified generic aggregated WPP model is therefore developed in this work for long term dynamic simulation studies, with starting point from the IEC 61400-27-1 Committee Draft [19]. However, for the specific purpose of this study, the model is further simplified and adjusted to reflect correctly the dynamic features for active power and frequency control capability studies, i.e., primary control from WPP.

The aggregated WPP model, as shown in Fig. 5, has a hierarchy structure, there is WPP active power control level

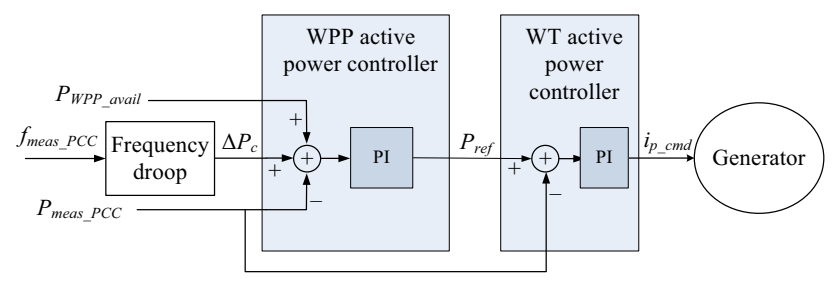

Fig. 5 Aggregated WPP model and a WT active power control level. The power reference $P_{\text {ref }}$ to the WT active power controller is generated by the WPP active power controller, based on the primary response signal $\left(\Delta P_{c}\right)$, the available wind power signal $\left(P_{W P P_{-} \text {avail }}\right)$ from the power balancing model and the measured power in the point of common connection (PCC). As shown in Fig. 5, the control both in the WT and in the WPP level is realised by using PI controllers. For example, the PI controller in the WPP active power controller can reduce the error between measured power at PCC $\left(P_{\text {meas_PCC }}\right)$ and the sum of the available power and the primary response signal $\left(P_{W P P}\right.$ avail $\left.\& \Delta P_{c}\right)$, in the decision of the $P_{\text {ref }}$.

The frequency droop block in Fig. 5, decides the $\Delta P_{c}$ for the aggregated WPP model, based on the droop setting. The typical value of $4 \%$ is used in this work for the droop setting. However, the primary response capability of WPP is strongly dependent on the availability of reserve power. An example in Fig. 6 shows the dynamic primary response from the WPP with a nominal power of $2800 \mathrm{MW}$, when a negative load step results in a frequency change of $-0.034 \mathrm{~Hz}$.

The new steady state response from the WPP is then calculated as follows:

$$
\begin{aligned}
\Delta P=-\Delta f \cdot \beta & =-\Delta f \cdot \frac{P_{W P P_{-} \text {nominal }}}{R \cdot f} \\
& =-(-0.034) \times \frac{2800}{0.04 \times 50}=47.6 \mathrm{MW} / \mathrm{Hz}
\end{aligned}
$$

Thus, following a load step, the WPP shares a load of 47.6 MW by increasing its production to stabilize the system frequency.

\subsection{Simulation results}

Different studies are carried out to assess the performance of the proposed active power control methodology. A set of simulations are performed using time series for generation, load and power exchange corresponding to one particular winter day. The time series is generated by SimBa for the scenario of the year 2020 for the Danish power

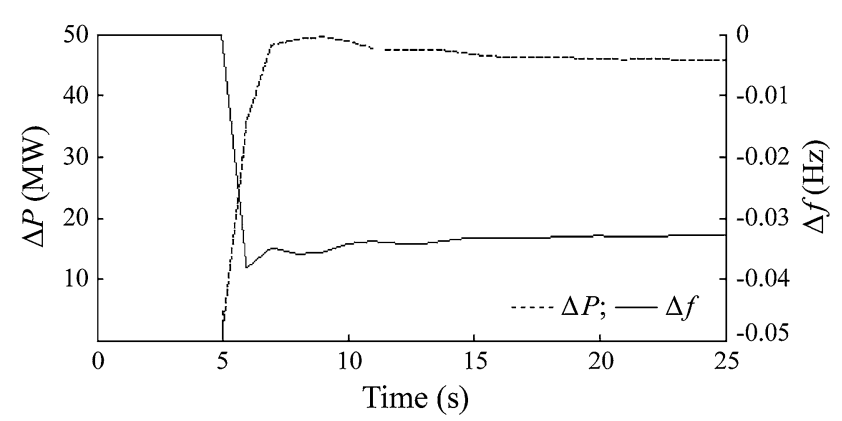

Fig. 6 WPP primary response for a load step 

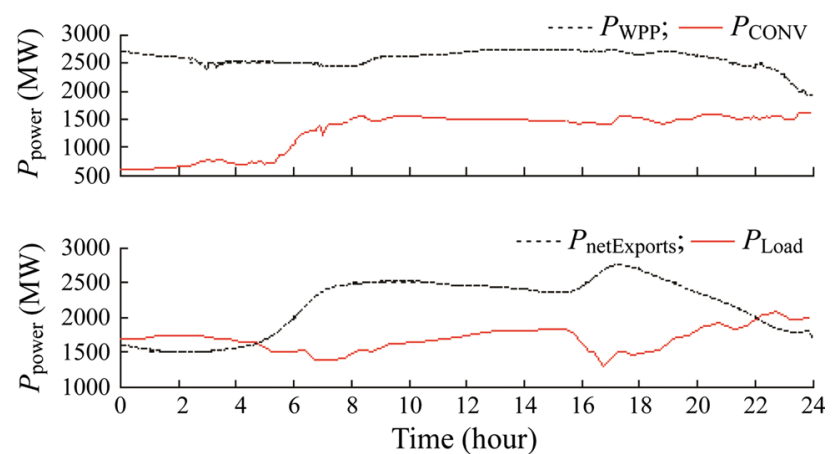

Fig. 7 Generation, load and net exports within the operating hourEast Denmark
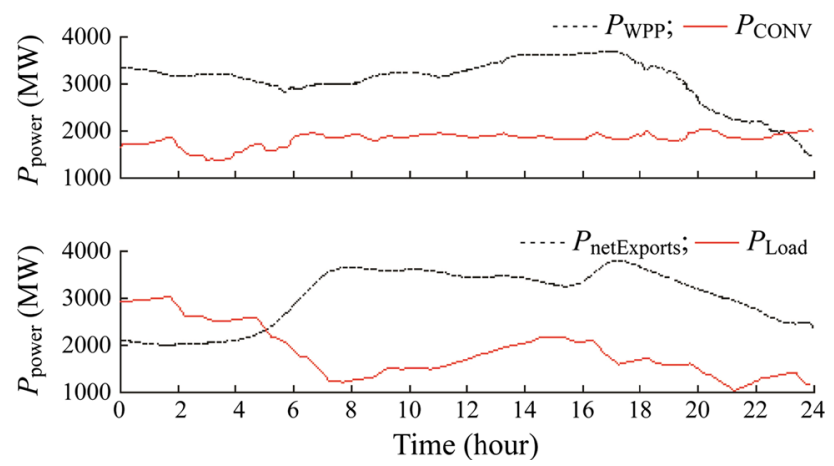

Fig. 8 Generation, load and net exports within the operating hourWest Denmark

system based on the real data from 2009. It is assumed that, the power exchange is kept at its planned level within the operating hour, while the conventional generating units change their power set point from the planned schedule as directed by AGC for any power imbalance. Fig. 7 and Fig. 8 show the power generated within the operating hour from conventional plants and wind power plants, as well as the net exports with neighbouring power systems and the load demand in the Eastern and Western Danish power systems are shown in Fig. 7 and Fig. 8, respectively. The net exports are calculated by subtracting the total import power from the total export power.

Some day the availability of wind allows the WPPs to generate more power than conventional power plants. In Eastern Denmark, the conventional power plants generate $30.81 \mathrm{GWh}$ of electricity, while WPPs generate 62.17 $\mathrm{GWh}$, i.e., $66.85 \%$ of the total electricity production. The high production from WPPs allows the net exports of $40.533 \mathrm{GWh}$ from Eastern Danish power system, when the load demand is $52.422 \mathrm{GWh}$. Alike in Western Denmark, $43.83 \mathrm{GWh}$ is generated from conventional power plants and $73.97 \mathrm{GWh}$ from WPP, i.e., $62.8 \%$. The total load demand and the net exports are $73.075 \mathrm{GWh}$ and 44.612 GWh, respectively. The generation from WPPs can meet the load demands in Eastern and Western Danish power systems, but the conventional power plants are operating to uphold the system reliability in case of unforeseen events. The availability of wind power and the high load demand, in the large scale wind power integrated power system, motivates to investigate the system behaviour on a particular day.

As aforementioned in Denmark, the electricity markets are balanced taking into account the hour-ahead forecasts of wind and load. If the available wind power generated within the operating hour differs from the forecast, a power mismatch between generation and load will appear. The power mismatch yields to a change at the system frequency and deviation in power exchange from its hour-ahead schedule. The generating units equipped with speed governors will respond to the deviations by releasing FCR. Afterwards, the FRR from the AGC, depending on reserves availability, will return the system frequency to its nominal level and consequently replaces FCR.

Fig. 9 shows the governor response from the WPP and conventional power plants as a result of wind power forecast error in Eastern and Western Danish power systems, respectively, while Fig. 10 shows the area control error $\left(P_{A C E}\right)$ after the AGC response $\left(\Delta P_{S E T}\right)$ in these power systems. The governor response depends on their droop setting and on their generating capacity. The WPP and the conventional power plants have the same droop setting, but the response is higher in case of WPP owing to its higher generation capacity, as shown in Fig. 9. However, the activation of FCR is subjected to reserves availability. These reserves are activated within $30 \mathrm{~s}$ and continue to be activated, as the power imbalance is changing continuously, until FRR through AGC removes the power imbalance.

The AGC continuously responds to the power mismatching between generation and load by providing new power set point to the generating unit and tries to reduce the power imbalance $\left(P_{A C E}\right)$ in the power system. However, the power imbalance in these power systems does not always return to zero level, as $\Delta P_{S E T}$ is limited to $\pm 90 \mathrm{MW}$ and also lags behind $P_{\mathrm{ACE}}$ due to the delays associated with the AGC and CHP, which abstains them to change their output at the required rate i.e., $P_{A C E}$ rate. These delays are caused due to the ramping in the reference power (i.e., 30 $\mathrm{MW} / \mathrm{min}$ ) and also due to the slow boiler response of CHP units (i.e. the boiler needs 5-6 min to modify its output pressure when demanded). The power imbalances deviate the system frequencies from their nominal level, as shown in Fig. 11, for the Eastern and Western Danish power systems.

The system frequency deviation, as shown in Fig. 11, relates to the amount of power imbalance. The surplus power results in frequency rise, while the deficit in 

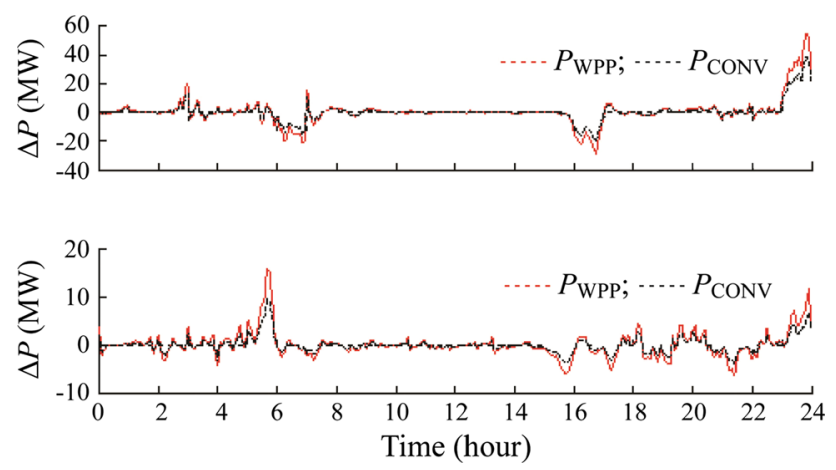

Fig. 9 Governor response to power imbalance-top: Eastern Denmark, bottom: Western Denmark
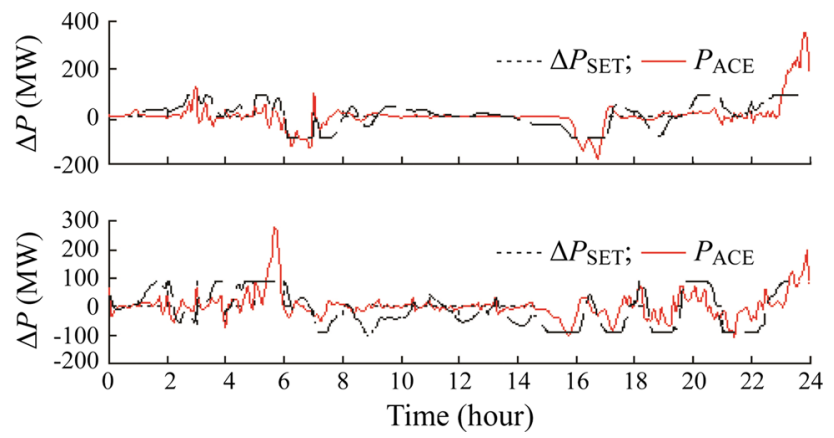

Fig. $10 P_{A C E}$ and $\Delta P_{S E T}$ from AGC-top: Eastern Denmark, bottom, Western Denmark

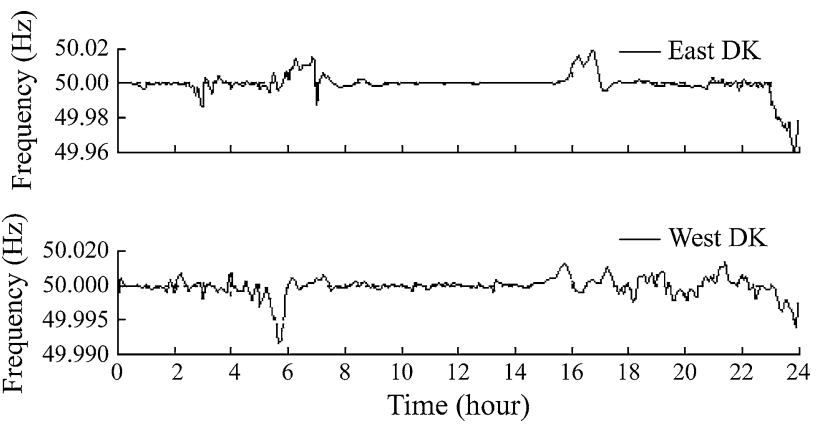

Fig. 11 System frequency

frequency drops. In spite of a large power imbalance, as shown in Fig. 12, the deviation in system frequency from its nominal level is insignificant, as the Danish power system is synchronously connected to the stiff and large continental European and Nordic power systems. The strong neighbouring interconnections offer huge frequency bias and stabilize the frequency in Danish power system. However, the power imbalance will divert the power exchange from its schedule and may overload the tie line. The secondary support from AGC will lower the real-time power imbalance arising due to the wind power forecast
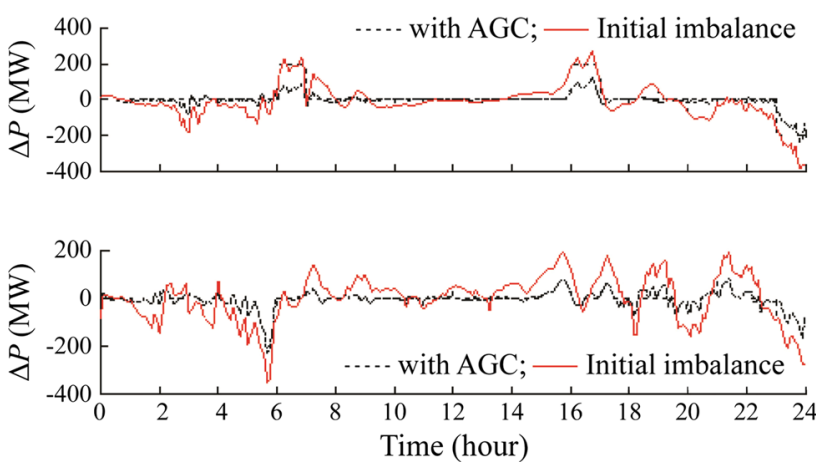

Fig. 12 Power imbalance with and without AGC-top: Eastern Denmark, bottom: Western Denmark

error. Fig. 12 shows the comparison of the power imbalances in the Eastern and Western Danish power systems with and without AGC support. The simulations show that the AGC system reduces the real time power imbalances and makes power system operation more reliable.

\section{Conclusion}

The integration of large amount of wind power into future power systems presents several challenges, for example the power system balancing and the availability of the regulating reserves. This paper describes and analyzes the challenges in the future power systems with the large scale integration of wind power. And then a methodology is proposed for the active power balance control taking into account the hourahead regulating power plan with reduced planning horizon. In the methodology, the power plants and the power exchange are dispatched in a time scale of $5 \mathrm{~min}$. The hourahead plan efficiently addresses the intermittent wind power and reduces the regulation burden that would be required in a dispatch plan of one hour. The AGC further compensates the power imbalances between demand and generation in a real time, which is provoked by wind power forecast errors. The Danish power system is used as a case study in this paper. The studies show that imbalances between the demand and the generation can be compensated by reducing dispatching plan and regulation the active power production from conventional power plants through AGC.

It has been illustrated through a set of simulations that the AGC can effectively control the real time power imbalances due to the wind power forecast errors, by controlling the generation from conventional power plants. Furthermore, it has been seen that the regulating reserves are needed from fast conventional power plants to maintain system balance and the amount depends on the level of wind power integration. Better forecasting of wind speed and the load demand is desirable in a power system of large-scale wind power integration. It has 
also been depicted that the interconnections with strong electrical networks stabilize the system frequency and decide the wind power integration level.

The proposed methodology provides guidelines on how large wind power can be integrate in the planning, control and operation of future power system. The WPP participation is further investigated in secondary frequency regulations by integrating the WPP control in the AGC system, to ensure secure and reliable operation of a power system of large-scale wind power integration. Another topic for future investigation can find the cost effective solution to deal with larger power imbalance in a power system of large-scale wind power integration.

Acknowledgement This paper is a part of Ph.D Project funded by Sino-Danish Centre for Education and Research (SDC).

Open Access This article is distributed under the terms of the Creative Commons Attribution 4.0 International License (http:// creativecommons.org/licenses/by/4.0/), which permits unrestricted use, distribution, and reproduction in any medium, provided you give appropriate credit to the original author(s) and the source, provide a link to the Creative Commons license, and indicate if changes were made.

\section{References}

[1] Suwannarat A (2008) Integration and control of wind farms in the Danish electricity system. PhD Thesis, Institute of Energy Technology, Aalborg University, Aalborg, Denmark

[2] Suwannarat A, Bak-Jensen B, Chen Z et al (2007) Power system operation with large scale wind power integration. In: Proceedings of the 2007 IEEE Lausanne power tech conference, Lausanne, Switzerland, 1-5 July 2007, pp 671-676

[3] Egido I, Fernández-Bernal F, Rouco L et al (2004) Modeling of thermal generating units for automatic generation control purposes. IEEE Trans Control Syst Technol 12(1):205-210

[4] Ummels BC, Gibescu M, Kling WL et al (2007) Performance of automatic generation control mechanisms with large-scale wind power. In: Proceedings of the Nordic wind power conference (NWPC'07), Roskilde, Denmark, 1-2 Nov 2007, 7 pp

[5] Li BH, Shen H, Tang Y et al (2001) Study on the frequency control method and AGC model of wind power integration based on the full dynamic process simulation program. In: Proceedings of the international conference on advanced power system automation and protection (APAP'11), Vol 1, Beijing, China, 16-20 Oct 2011, pp 246-251

[6] Sørensen P, Norheim I, Meibom P et al (2007) Simulations of wind power integration with complementary power system planning tools. Electr Power Syst Res 78(6):1069-1079

[7] Basit A, Hansen AD, Altin M et al (2014) Wind power integration into the automatic generation control of power systems with large-scale wind power. J Eng. doi:10.1049/joe.2014.0222

[8] Abbad JR (2010) Electricity market participation of wind farms: the success story of the Spanish pragmatism. Energy Policy 38(7):3174-3179

[9] Grande OS, Doorman G, Bakken BH (2008) Exchange of balancing resources between the Nordic synchronous system and the Netherlands/Germany/Poland. TR A6652, SINTEF Energiforskning AS, Trondheim, Norway

[10] Meibom P, Morthorst PE, Nielsen LH et al (2003) Power system models - a description of power markets and outline of market modelling in Wilmar. Ris $\varnothing-\mathrm{R}-1441(\mathrm{EN})$, Ris $\varnothing$ National Laboratory, Roskilde, Denmark

[11] Meibom P, Barth R, Norheim I et al (2006) Wind power integration in a liberalised electricity market. Final Technical Report, Ris $\varnothing$ National Laboratory, Roskilde, Denmark

[12] Barth R, Weber C (2005) WILMAR, deliverable D7.1: distribution of the integration costs of wind power. Institute of Energy Economics and the Rational Use of Energy, University of Stuttgart, Stuttgart, Germany

[13] Meibom P, Larsen HV, Barth R et al (2006) WILMAR, deliverable D6.2(b): WILMAR joint market model documentation. Ris $\varnothing-R-1552(E N)$, Ris $\varnothing$ National Laboratory, Roskilde, Denmark

[14] Hansen AB, Orths A, Falk K et al (2011) Danish fossil independent energy system 2050: from strategic investigations to intra-hour simulation of balancing issues. In: Proceedings of the 10th international workshop on large-scale integration of wind power into power systems, Aarhus, Denmark, 25-26 Oct 2011

[15] P1-Policy 1: Load-frequency control and performance (2010) The European network of transmission system operators for electricity (ENTSO-E), Brussels, Belgium

[16] Skødt T (2014) Electricity interconnections. Energinet.dk, Fredericia

[17] Byerly RT, Aanstad O, Berry DH et al (1973) Dynamic models for steam and hydro turbines in power system studies. IEEE Trans Power Appar Syst 92(6):1904-1915

[18] CIGRE Task Force 25 of Advisory Group 02 of Study Committee C4 (2003) Modeling of gas turbines and steam turbines in combined cycle power plants. CIGRE, Paris

[19] IEC 61400-27-1 Committee Draft (2012) Wind turbines, Part 27-1: electrical simulation models-wind turbines

Abdul BASIT received the B.Sc. degree in electrical engineering from the University of Engineering \& Technology, Peshawar, Pakistan in 2006 and M.Sc. degree in electrical power engineering from Chalmers University of Technology, Sweden in 2011. He is currently employed as a PhD student at Department of Wind Energy of the Technical University of Denmark (DTU). His research interest includes integration of wind power into power systems, automatic generation control, wind power plant control, and power systems.

Anca D. HANSEN received the degree in aerospace engineering from the Technical University of Bucharest, Romania, in 1992 and a $\mathrm{Ph} . \mathrm{D}$. degree in modelling and control engineering from Denmark Technical University in 1996. In 1998, she joined Ris $\varnothing$ National Laboratory, working first as PostDoc and then a scientist with modelling and control of wind turbines. Today, she is working as Senior Scientist in the DTU Wind Energy department, former Ris $\varnothing$ National Laboratory, in Denmark. Her research interest is integration of wind power into power systems, involving different technical topics on dynamic modelling and control of wind power plants, ancillary services as well as power system control and stability topics. She is author or co-author of more than 100 journal/conference papers, several research reports in her research fields.

Mufit ALTIN received B.Sc. and M.Sc. degrees in electrical and electronics engineering from the Middle East Technical University (METU), Ankara in 2004 and 2009, respectively He obtained his PhD degree from the Department of Energy Technology, Aalborg University, Denmark, in 2012, where he was employed as a researcher under the Vestas Power Programme during his $\mathrm{PhD}$. $\mathrm{He}$ 
joined and is currently working as a postdoc at Department of Wind Energy of the Technical University of Denmark (DTU). His research interest includes distribution automation, wind power plant control, wind energy, and power systems.

Poul E. SØRENSEN was born in 1958. He received the M.Sc. degree in electrical engineering from the Technical University of Denmark, Copenhagen, Denmark, in 1987. Since 1987, he has been at Ris $\varnothing$ National Laboratory, Roskilde, where he is currently a Professor. His research interests include integration of wind power into power systems, involving a variety of technical disciplines including power system control and stability, dynamic modeling and control of wind turbines and wind farms, and wind fluctuation statistics. Prof. Sørensen is convener of the IEC 61400-27 working group.

Mette GAMST received B.Sc. and M.Sc. degrees in computer science from the University of Copenhagen, Denmark in 2004 and 2007, respectively She obtained her $\mathrm{PhD}$ degree from the DTU Management Engineering, Technical University of Denmark in 2010. She is currently working as system analyst in Energinet.dk. 